\title{
THE
}

\section{A decade comparison of preterm motor performance at age 4}

\author{
Mary C. Sullivan \\ University of Rhode Island, mcsullivan@uri.edu \\ Kathleen Hawes \\ University of Rhode Island
}

Follow this and additional works at: https://digitalcommons.uri.edu/nursing_facpubs

This is a pre-publication author manuscript of the final, published article.

\section{Creative Commons License}

\section{c) (i) $\Theta$}

This work is licensed under a Creative Commons Attribution-Noncommercial-No Derivative Works 4.0 License.

\section{Citation/Publisher Attribution}

Sullivan, M. C. and Hawes, K. (2007), A decade comparison of preterm motor performance at age 4. Res. Nurs. Health, 30: 641-654. doi: 10.1002/nur.20220

Available at: https://doi.org/10.1002/nur.20220

This Article is brought to you for free and open access by the College of Nursing at DigitalCommons@URI. It has been accepted for inclusion in College of Nursing Faculty Publications by an authorized administrator of DigitalCommons@URI. For more information, please contact digitalcommons-group@uri.edu. 


\title{
A Decade Comparison of Preterm Motor Performance at Age 4
}

\author{
Mary C. Sullivan ${ }^{1,2,{ }^{*}}$ and Katheleen Hawes ${ }^{1,2,{ }^{* *}}$ \\ ${ }^{1}$ College of Nursing, University of Rhode Island, Kingston, RI \\ ${ }^{2}$ Women \& Infants Hospital, Brown Center for the Study of Children at Risk, Providence, RI
}

\section{Abstract}

This was a prospective longitudinal study of two cohorts comprised of one full term and three premature infant groups born 10 years apart. Birth cohort, perinatal morbidity, and birth weight effects were investigated at age 4. Cohort 1 (1985-1989) had longer gestation, higher birth weight, and better Apgar scores than Cohort 2 (1996-1999), which had more intraventricular hemorrhage and bronchopulmonary dysplasia. Cohort and perinatal morbidity group, but not birth weight, predicted motor scores. Preterm Cohort 2 children had better oral motor, fine motor, and total motor scores, but lower visual motor integration scores than Cohort 1. Motor problems continue to affect preterm children at age 4 , in particular those who experience perinatal morbidity, despite a decade of neonatal intensive care advancements.

In $2004,12.5 \%$ of the 4 million infants born in the U.S. were premature, an $18 \%$ increase since 1990 and a 30\% since 1981 (Martin et al., 2006). Prenatal steroids, surfactant for respiratory distress syndrome, indomethacin to prevent intraventricular hemorrhage, better feeding and nutrition, and improved pulmonary ventilation are credited for increased survival rates, especially for those with birth weight under 1,000 $\mathrm{g}$ born in the decades of the 1980s and 1990s (Hack \& Fanaroff, 1999; O’Shea, Klinepeter, Goldstein, Jackson, \& Dillard, 1997; Vohr \& Msall, 1997). Although disability and severe impairment rates have remained stable, attention has shifted to high prevalence/low-severity dysfunctions occurring in an estimated 50-70\% of infants (Aylward, 2003; O'Shea et al.). Given these high rates and the increased numbers of preterm survivors, it is important to know whether improvements in neonatal care have improved outcomes at pre-school age. This knowledge could inform Neonatal Intensive Care Unit (NICU) practices and help gauge the future costs and burden for families, and for health care and community systems. In this study we compared two cohorts of preterm infants born a decade apart, using identical group categorization, to examine whether a decade of advancement has improved motor performance at age 4 years.

One prevalent finding in prematurely born children without major handicap is impaired motor function, which becomes evident at pre-school age (Bowen et al., 1993; Lie, 1994). By age 4, the child has matured developmentally to be able to perform specific motor activities efficiently and to use them automatically (Touwen, Hempel, \& Westra, 1992). Yet, compared to full term children, many preterm children have poor balance, poor muscle tone, less skill in gross motor function, and more spontaneous movements indicative of delayed

\section{(c) 2007 Wiley Periodicals, Inc.}

Correspondence to Mary C. Sullivan, College of Nursing, University of Rhode Island, White Hall, Kingston, RI 02881.

***ofessor.

*** Doctoral Student.

Margaret M. McGrath, DNSc, RN, FAAN was the Principal Investigator of cohort 1, Developmental Outcome of 4-Year-Old Children Born at Risk. 
neurological maturation (Stjernqvist \& Svenningsen, 1995; Wildin, Smith, Anderson, Swank, \& Landry, 1997). Children with medical or neurological perinatal morbidity and mild motor problems at preschool age are apt to have learning and school performance difficulties at school age (Powls, Botting, Cooke, \& Marlow, 1995; Sullivan \& McGrath, 2003).

An understanding of the pathways of perinatal morbidity and developmental outcomes must incorporate the effects of birth weight, as the lowest birth weight infants are often at greatest risk for poor outcomes (Aylward, 2002). Severe neurosensory disability rates range from 19 to $57 \%$, while severe impairments range from 9 to $37 \%$ for children born $<800 \mathrm{~g}$ in the 1990s (Hack \& Fanaroff, 1999). Although disability increases with decreasing birth weight, not all extremely low birth weight $(<1,000 \mathrm{~g})$ children have impairment, and some low birth weight (1,501-2,500 g) children have impairment, suggesting that postnatal morbidities also play a role in outcomes.

Preschool motor function at age 4 may be determined by the interrelationship of perinatal morbidity and birth weight, within the context of advances in neonatal medical care. Our conceptual framework is neurobiological, viewing the preterm infant at risk for double jeopardy (Aylward, 2005; Taylor, Burant, Holding, Klein, \& Hack, 2002). First, the early birth may be associated with incomplete prenatal brain growth and myelination, which are dependent on gestational age. Volpe (1997) noted an intrinsic vulnerability of the immature oligodendrocyte in neonatal cerebral white matter due to oxidative stress and injury from free radical formation. In the process of cerebral myelination, proximal pathways myelinate before distal and sensory pathways, and myelination of motor pathways occurs last. The risk of damage to motor pathways may double with the effect of perinatal illness. Subcortical white matter is especially vulnerable to ischemic injury and metabolic insults before 32 weeks gestation because of vascular and cellular factors hypothesized to be related to perinatal illnesses (Volpe, 1998). Due to the proximity of periventricular infarctions to the cortical tracts, the risk of motor problems is ubiquitous in these children.

The purpose of this study was to investigate the effects of birth cohort, perinatal morbidity, and birth weight on preschool general motor, gross motor, fine motor, and visual motor integration in two samples of children born prematurely 10 years apart, and a comparison sample of full term infants. The two cohorts included 152 children born between 1985 and 1989 (Cohort 1) and 155 children born between 1996 and 1999 (Cohort 2). With technological advances in perinatal and neonatal care, we expected Cohort 2 to have lower birth weight and younger gestational age than Cohort 1 (Hypothesis 1), and we hypothesized an associated decline in motor performance between decades, with poorer performance for Cohort 2 (Hypothesis 2). Regarding perinatal morbidity, we hypothesized poorer motor scores at age 4 for the preterm infants in both cohorts with neurological and/or medical morbidity compared to the children born full term (Hypothesis 3 ).

\section{METHOD}

\section{Sample}

This was a four group prospective, longitudinal study of two cohorts. The recruitment criteria were neonatal diagnoses, birth weight, maternal mental health (no history of mental illness), and English as a primary language due to limited availability of translators and use of English-only standardized instruments. Preterm was defined as $<1,850 \mathrm{~g}$ and $<37$ weeks gestational age. Infant and maternal medical charts were screened to determine eligibility for recruitment. Prior to recruitment, socioeconomic status (SES) was estimated from parent demographics and health insurance coverage so that there were approximately equal numbers of high (33\%), middle (33\%), and low (33\%) SES in each of the study groups. 
After recruitment, SES was measured by the Hollings-head four factor scale (Hollingshead, 1975). No significant difference in SES within the groups or between cohorts was found at birth and age 4.

The study group criteria were: (a) full term healthy infants (FT); (b) preterm infants with medical illness [MPT: bronchopulmonary dysplasia (BPD), respiratory distress syndrome (RDS), necrotizing enterocolitis (NEC), sepsis] and birth weight <1,000 g (MPT1); (c) preterm infants with medical illness and birth weight $\geq 1,000 \mathrm{~g}$ (MPT2); and (d) preterm infants with neurological illness [NPT: meningitis, hydrocephalus, grade 3 or 4 intraventricular hemorrhage (IVH)]. The definitions used for BPD, RDS, NEC, sepsis, and IVH were the same for both cohorts. BPD was defined as oxygen requirement at 28 days of life. RDS required diagnosis within the first 2 days, based on typical signs (grunting and retractions) and characteristic chest radiograph findings. NEC was classified using Bell's criteria (Bell et al., 1978). Sepsis was defined as high clinical suspicion with administration of antepartum antibiotics, plus all culture-positive episodes. IVH was classified according to the highest Papile grade (Papile, Burstein, Burstein, \& Koffler, 1978).

Both cohorts were recruited from the same large tertiary medical center. During the two epochs studied, the number of deliveries of infants aged $\geq 20$ weeks gestational age ranged from approximately 7,700 to 8,500 annually. The race/ethnicity distribution was stable during the study times and closely reflected that of the region (Women \& Infants Hospital, 1999). Maternal self-identification for Cohort 1 was: White, non-Hispanic (87\%), Hispanic (4\%), African-American (8\%) and Other (.5\%). Maternal self-identification for Cohort 2 was: White, non-Hispanic (73\%), Hispanic (8\%), African-American (9\%), Asian (.6\%) and Other $(8 \%)$. The infants in both cohorts received the standard of care at the time, including referrals for occupational therapy, early intervention services, and visiting nurse services.

The Cohort 1 sample, born between October 1985 and June 1989, was recruited to study acoustic cry and later neurodevelopmental outcomes of preterm infants. Potential preterm infants were identified from a medical chart screening during the mother's post-partum stay or the infant's NICU stay. A comparison group of full term infants was recruited in the same time period. Cohort $1(N=152)$ included 39 normal, healthy full term infants delivered by mothers with uncomplicated labors and deliveries and a heterogeneous group of 113 preterm infants, classified into the three a priori perinatal morbidity groups, with $n$ 's ranging from 23 to 53 (see Table 1). Fewer than $10 \%$ of the parent(s) declined participation when approached for recruitment. Ninety-eight percent of Cohort 1 participated at age 4 . Of the 4 children who were not seen at age 4, there were 2 refusals (2 NPT) and 2 lost to tracking (1 FT, 1 MPT).

The inclusion criteria for Cohort 1 were replicated a decade later for Cohort 2, born between April 1996 and March 1999. All possible infants who met inclusion criteria were identified from the hospital medical records database followed by random number sampling. These infant medical records were reviewed by either of two nurse practitioners or the first author to assure that sample criteria were met. Families were invited to participate, first by mail followed by a phone call when the child was within 2 months of their fourth birthday. Cohort 2 sample $(N=155)$ included 43 full term infants and 112 preterm infants using the same group classification ( $n$ 's ranging from 32 to 42 , see Table 1). Families were very willing to participate, with only 9 of 164 potential participants not enrolled due to refusals ( $n$ $=2$ ) or unable to track or moved from the region $(n=5)$. Two families of FT infants declined due to the child's recent diagnoses ( 1 with celiac disease; 1 with multiple developmental delays). 
The mean age for children was 47.4 months ( $S D=1.9$; range 42-58) for Cohort 1, and 49.1 months ( $S D=1.3$; range $46-54$ months) for Cohort 2 . There was no correction for prematurity at age 4 .

\section{Measures}

Infant measures included birth weight, gestational age, Apgar scores, length of hospitalization, discharge weight, and neonatal illnesses recorded from hospital medical charts. For Cohort 1, infant risk was measured by the Hobel Neonatal Scale (Hobel, Hyvarinen, Okada, \& Oh, 1973), which weights risk of neonatal illness by body systems (i.e., respiratory, circulatory, hematological, and metabolic). Each weighted item is summed for a total risk score. The Hobel was outdated for Cohort 2, therefore the Score for Neonatal Acute Physiology (SNAPII; Richardson, 1999) was used. The SNAPII is a physiology based score that uses routinely available vital signs and laboratory results representing physiological derangements to assess illness severity (Richardson, Corcoran, Escobar, \& Lee, 2001). There are six weighted items of physiological measures and three weighted supplemental perinatal mortality risks (birth weight, small for gestational age, Apgar score) that are summed for a total score. Higher scores indicate higher neonatal risk. In both cohorts, NICU nurses or nurse practitioners extracted the neonatal data and calculated the risk score as each infant was recruited. Interrater reliability agreement was $97 \%$ for the Hobel and $98 \%$ for the SNAPII. When discrepancies or questions arose from the chart review, they were brought to the consulting neonatologist for discussion and final determination.

At age 4, identical measures were used in both cohorts to assess general motor, gross motor, fine motor, and visual motor integration. The measures have demonstrated validity with test reliability correlation ranges of .77 -.92 and internal consistency ranges of .75- .91 , and they have been extensively used in pediatric research and preterm samples (Collin, Halsey, \& Anderson, 1991; Piecuch et al., 1997; Saigal et al., 1994; Wildin et al., 1997). The motor scale of the McCarthy Scales of Children's Abilities (MSCA; McCarthy, 1972) was used to assess the child's coordination in a variety of gross and fine motor tasks. Gross motor items include Arm Coordination (6 items), Leg Coordination (6 items) and Imitative Action (4 items), and fine motor items include Draw-A-Design (9 items) and Draw-A-Child (10 items). Stability coefficients for the Motor Scale ranged from .75 to. 78 , and the MSCA is a significant predictor of first grade achievement scores. The standardized mean is 50 ( $S D$ $=10$ ) with higher scores indicative of better motor performance.

The Riley Motor Problem Inventory (RMPI; Riley, 1976) assesses oral, fine, and gross motor dimensions. It is designed to identify neurological 'soft signs' by testing motor components of early childhood problems in speech, language, movement, and behavior. Eleven items are summed to form a total score and three subtest scores; oral motor, fine motor, and gross motor. Scores range from 6 to 20 with higher scores indicative of more motor problems. Reliability estimates range from .77 to .91 . Separate unpublished data show the RMPI correlated with the Bender-Gestalt (.62) and the Human Drawing Test (.74; Riley).

The Beery Developmental Test of Visual-Motor Integration (VMI) assesses the degree to which visual perception and motor behavior are integrated to help identify significant difficulties in coordination of visual perceptual and motor (finger and hand movement) capacities (Beery, 1982, 1997). The VMI and its supplemental visual and motor tests were normed on 2,614 children from 3 to 18 years of age, from 5 major sections of the United States. The standardized mean is $100(S D=15)$, with higher scores indicating better visual motor integration. The Rasch-Wright results indicate high content reliability for the VMI, as its total group item separation was 1.0 and its total group person separation was .99. Internal 
consistency at age 4 was .86 , average inter-scorer reliability was .92 . Concurrent validity is demonstrated by significant correlation with both the Developmental Test of Vision Perception and the Drawing subtest of the Wide Range Assessment of Visual Motor Abilities (Beery, 1997).

\section{Procedures}

The motor testing at age 4 was done as part of a research assessment, either in the hospital research laboratory or during a home visit. During the visit, informed consent was obtained, demographic and health data were collected by interviewing the parent(s), and the motor assessments were completed. Test administration was standardized according to manual directions. Protocol training was completed by study personnel in both cohorts, with reliability maintained above $85 \%$ agreement across settings and across cohorts. The Principal Investigator for the Cohort 1 study consulted on the Cohort 2 protocol and the Principal Investigator of the Cohort 2 study was a research nurse for the Cohort 1 study. Institutional Review Board approval was obtained from both hospital and university for each cohort study.

\section{Analyses}

Multivariate ANOVA was used to test the first hypothesis concerning differences and interaction effects between cohorts and perinatal morbidity group on the neonatal variables of birth weight, gestational age, Apgar scores, length of hospitalization and discharge weight. Chi Square was used for the categorical morbidities. Multivariate ANOVA models were used to test the second hypothesis concerning the main effects and their interactions for general motor, oral motor, fine motor, gross motor, total motor, and visual motor integration scores at age 4 . For these analyses, the design variables were (a) birth weight, (b) perinatal morbidity group, and (c) birth cohort. We followed significant multivariate models with univariate analysis to test the third hypothesis. Duncan's Multiple Range Test was used post hoc to test pairwise differences.

We computed power for a MANOVA design with two factors and six dependent variables using the PASS software (Hintze, 2004) with an alpha level of .05 for main effects and interactions. The design achieves $95 \%$ power to detect small effects for the sample shown in Tables 3 and 4 . The univariate ANOVAs had better than $90 \%$ power to detect significant main effects and interactions.

\section{RESULTS}

\section{Neonatal Findings}

The multivariate ANOVA was significant for cohort [Lambda(5, 271) $=11.01, p=.001]$, perinatal morbidity group $[\operatorname{Lambda}(15,748)=114.289, p=.001]$, and their interaction $[\operatorname{Lambda}(15,748)=2.2, p=.005]$ for the dependent variables of birth weight, gestational age, 5 minute Apgar score, length of hospitalization, and discharge weight. The interaction of cohort $\times$ perinatal morbidity showed that gestational age and birth weights were lower for the MPT1 and NPT groups in Cohort 2 compared to Cohort 1, supporting Hypothesis 1. The FT groups did not differ between cohorts.

Differences between cohorts showed that Cohort 1 had higher gestational age [ $M=32.2, S D$ $=4.7 ; F(1,283)=32.77, p=.001]$ and higher Apgar scores $[M=7.7, S D=1.4 ; F(1,283)=$ $11.16, p=.001$ ] than Cohort 2 [gestational age $(M=31.0, S D=6.0)$; Apgar $(M=7.1, S D=$ 2.0)]. Cohort 2 infants had greater discharge weight $(M=2612.6, S D=720.5)$ than Cohort 1 $(M=2362.7, S D=588.6)$. Cohort 2 had higher rates of IVH [Chi Square $(4,205)=26.75, p$ $=.001]$ and BPD [Chi Square $(1,262)=16.3, p=.001]$. Almost half the morbidity for the 
Cohort 2 premature infants was BPD $(n=53,47 \%)$ compared to $24 \%(n=27)$ for Cohort 1 (see Fig. 1). Cohort 2 had more infants with sepsis and IVH grade 3 or 4 , and the incidence of NEC and seizures was slightly lower than Cohort 1. Children in the high acuity NPT group had multiple morbidities. Figure 2 shows that more NPT children in Cohort 2 had two or three additional medical morbidities than Cohort 1 (45\% vs. 14\%). The occurrence of neurological morbidity only (no additional medical illness) was greater for Cohort 1 (12\% vs. $41 \%$ ). The occurrence of just one medical co-morbidity was comparable for the NPT groups in each cohort ( $44 \%$ and $41 \%)$. The descriptive statistics for neonatal characteristics within each cohort are presented in Table 1.

\section{Preschool Motor Findings}

The multivariate ANOVA for preschool motor scores was significant for Cohort [Lambda(5, $285)=19.3, p=.001]$ and perinatal morbidity group $[\operatorname{Lambda}(10,570)=3.20, p=.001]$. Birth weight and the interactions, cohort $\times$ perinatal group, cohort $\times$ birth weight, birth weight $\times$ perinatal group, were not significant. Cohort had the largest explained variance (eta squared $=.259$ ), followed by perinatal morbidity (eta squared $=.053$ ), and birth weight (eta squared $=.012)$. The univariate analyses showed that oral motor $[F(1,303)=24.6, p=.001]$, fine motor $[F(1,303)=12.09, p=.001]$, total motor $F(1,303)=17.00, p=.001]$ and visual motor integration $[F(1,303)=52.49, p=.001]$ were different between cohorts. Cohort 2 had better oral motor, fine motor, and total motor scores than Cohort 1 . Cohort 1 had better visual motor integration scores than Cohort 2 (see Table 2). Thus, Hypothesis 2, that motor scores would be lower for Cohort 2 than Cohort 1, was only partially supported.

Mean motor scores were within the normal range for all groups except the NPT group in both cohorts. Contrary to Hypothesis 2, the preterm children (MPT1, MPT2, NPT) in Cohort 2 had better motor scores than the preterm children born 10 years earlier when matching perinatal morbidity group across cohorts. The Cohort 1 MPT1 group had poorer scores than Cohort 2 MPT1 in oral motor, fine motor, and total motor. For the MPT2 groups, Cohort 2 scores were higher for oral motor and total motor. However, the visual motor integration score was lower for the MPT groups of Cohort 2. The only pairwise cohort difference for the NPT groups was in visual motor integration: Cohort 1 had higher scores (see Table 2).

Given the findings for visual motor integration, we examined the frequency of vision problems at age 4 for both Cohorts from parental and pediatrician health history data. We used a bivariate code of normal (no vision problems) and vision problems (strabismus, nystagmus, myopia, hyperopia, peripheral loss, blindness, suspect conditions such as continued follow-up of retinopathy of prematurity, and color-blindness). FT children in Cohort 1 had normal vision. Nineteen percent $(n=21)$ of the preterm children had vision problems: $9.5 \%(n=5)$ from the MPT2 group; $26 \%(n=6)$ from the MPT1 group; and 27\% $(n=10)$ from the NPT group. With the exception of the MPT1 group, there were greater numbers of children from Cohort 2 with vision problems $(24 \%, n=27): 7 \%(n=3)$ from the FT group; $12.5 \%(n=5)$ from the MPT2 group; $17.5 \%(n=7)$ from the MPT1 group; and $45.2 \%(n=14)$ from the NPT group. A $2 \times 2 \times 4$ multivariate analysis confirmed significant interactions for cohort $\times$ vision on general motor $[F(1,302)=7.3, p=.007]$ and total motor $[F(1,302)=6.1, p=.014]$, showing that the children in Cohort 2 with vision problems had lower motor scores compared to children in Cohort 1 . There was an interaction of perinatal group $\times$ vision on visual motor integration $[F(3,302)=3.4, p=.018]$ showing that children with vision problems in the FT, MPT2, and NPT groups had lower visual motor integration scores. There were no significant interaction effects for fine and gross motor outcomes. 


\section{Group Effects Within Cohorts}

For Cohort 1, there were significant group differences for five of the six motor dimensions, partially supporting Hypothesis 3; only oral motor was not significant (see Table 3). The FT group had the best scores on all measures (i.e., lower scores on the RMPI). The MPT2 group had better scores than the NPT group. The MPT2 group scores did not differ from the FT group on fine motor, gross motor, and total motor. Mean scores for the MPT1 group and NPT group were the poorest and not significantly different from each other.

For Cohort 2, there were significant group differences for all six motor measures, supporting Hypothesis 3 (see Table 4). The FT, MPT1 and MPT2 had significantly better scores than the NPT group on oral motor and total motor outcomes. On fine motor, the FT had the best score, the MPT1 and MPT2 were significantly poorer, and the NPT had the poorest scores. For gross motor and visual motor integration, FT and MPT2 had better scores than the MPT1 group, which had better scores than the NPT group. The MPT1 and MPT2 groups had visual motor integration scores comparable to the FT group, while in general motor, the MPT2 and MPT1 groups were not significantly different from each other. All groups were significantly better than the NPT group. In contrast to Cohort 1 results, the MPT1 group scores were significantly better than the NPT group.

\section{DISCUSSION}

While neonatal advances have improved survival at lower birth weights for preterm infants born in the late 1990s compared to the late 1980s, the prevalence of major morbidity has increased with lower birth weights $(<1,000 \mathrm{~g})$. Prevalence of lower severity neurodevelopmental disabilities has remained stable through the early 1990s (Hack \& Fanaroff, 1999; Lee et al., 1995). Our infancy data show some effect of this pattern of change over a decade of neonatal advances. The preterm groups in Cohort 2 had lower birth weights and were hospitalized for longer periods than those in Cohort 1 . The percentage of infants with birth weights less than 1,000 g was larger in Cohort 2 (MPT 51\%, NPT 57\%) than Cohort 1 (MPT 30\%, NPT 38\%). There was an increase in specific perinatal morbidities in Cohort 2, including Grades 3-4 IVH and hydrocephalus in the NPT group, and BPD, pneumonia, and sepsis in the MPT groups. NPT infants in Cohort 2 had more coexisting medical morbidities. In a regional cohort comparison study of premature infants <32 weeks gestation, rates of BPD increased from 6 to 19\% between 1983 and 1996-1997 (Stoelhorst et al., 2005). Smith et al. (2005) reported that the rates of BPD have not declined in the post-surfactant era, but rates of severe BPD have. In this study, BPD was defined as oxygen requirement at 28 days of life. Using the definition of severe BPD as oxygen requirement at 36 weeks post conceptual age, the BPD rate for all infants $<1,000 \mathrm{~g}$ in this study was approximately $24 \%$, the lower range for the NICHD Neonatal Research Network centers during the mid-1990s (Vohr et al., 2004).

Mortality and morbidity rates and clinical practices are known to vary considerably among NICUs. This phenomenon makes for both inherent limitations and advantages to single center studies. Among several benefits from a longitudinal study of outcomes at a large, regional perinatal center are its population-based attributes and consistency of obstetric and neonatal practices. Internally consistent perinatal and NICU practice styles at the study institution were documented during the SNAP II Study Group of New England NICUs (AlAweel et al., 2001; Bednarek et al., 1998; Kahn et al., 1998; Richardson et al., 1999) and in site-specific data from the NICHD Neonatal Research Network (Vohr et al., 2004). However, several significant changes in clinical practice and technology occurred between the Cohort 1 and Cohort 2 epochs. Use of antenatal steroids for women in preterm labor was uncommon $(<35 \%)$ for Cohort 1, but was nearly universal for Cohort 2. In Cohort 2, more than $90 \%$ of infants $<1,000 \mathrm{~g}$ received surfactant treatment; high frequency ventilation use 
also was more common. Finally, Cohort 2 infants with birth weights $<1,250 \mathrm{~g}$ routinely received indomethacin as IVH prophylaxis (Ment et al., 1994). These neonatal advances occurring within our center may account for some cohort differences. Time-appropriate neonatal risk indices were used for both cohorts, but due to NICU advances, they are not entirely comparable between cohorts, making it impossible to compare cumulative neonatal acuity across the decade. There is recent evidence that while neonatal severity indices are good predictors of short term neonatal outcomes, they are not predictive of 4-year psychomotor, neurosensory, hearing and vision impairment, concentration difficulties, and growth (Eriksson, Bodin, Finnstrom, \& Schollin, 2002). Thus, comparable neonatal risk indices would not be helpful in estimating preschool aged outcomes.

The significant cohort effects show that pre-school outcomes in fine, gross, total, and general motor abilities improved for the preterm children born in the late 1990s compared to preterm children born in the 1980s, but visual motor integration has declined. Explanations for these differences might include history effects of the intervening 10 years. Though this threat to internal validity cannot be eliminated, the inclusion of a full term comparison group was a solid strategy. We would expect a decade of events also to be evident in betweencohort differences in the full term groups because the measures were standardized for healthy full term children. Yet, the two FT groups born a decade apart did not differ in motor outcomes at age 4. SES, another source of between cohort differences, was controlled in our study design using the identical measure for each cohort. No SES differences were found. Although we used a neurobiological framework, we acknowledge the value of a developmental science perspective where an interplay of biology and environment affects child outcomes such as cognition and behavior (McGrath \& Sullivan, 2003).

When compared to full term peers, the preterm children at age 4 had poorer motor performance despite a decade of improved NICU technology. However, mean scores were within the normal range for all groups except the NPT groups. In both cohorts premature children with neurological illness (NPT) had the poorest general, gross, fine, and visual motor function compared to other preterms and full term children. When 22 children in both cohorts (11 in each) with severe disability were removed from the analyses, the results were unchanged, showing that preterm children with medical and/or neurological morbidity but without severe disability continue to have motor problems at age 4. Similar findings by Caravale, Tozzi, Albino, and Vicari (2005) showed lower scores at age 3-4 years in visual perception and visual motor integration for healthy preterm children with normal intelligence and without neurodevelopmental deficits who were born at 30-34 weeks gestation.

The long term effects of neonatal morbidity have been reported by others. Creasey, Jarvis, Myers, Markowitz, and Kerkering (1993) found that preterm children with respiratory illness scored lower in motor ability than healthy preterms. The hypoxic effect of BPD has been associated with poor school age motor coordination, poor postural control, and fine and gross motor delay (Majnemer et al., 2000; Shevall \& Majnemer, 1996). Two research groups (Blitz, Wachtel, Blackmon, \& Berenson-Howard, 1997; Singer, Yamashita, Lilien, Collin, \& Baley, 1997) with large samples of preterm infants with BPD born between 1989 and 1991 found delay in motor skills at $8,12,24$, and 36 months of age, and that BPD predicted poor motor outcome at ages 2-3 years, after controlling for other risks of gestational age, sex, race and SES. At age 5 years, Goyen, Lui, and Woods (1998) found poor fine motor and visual motor integration skills in children who had hyaline membrane disease and were ventilated more than 8 days, but not in children with IVH, NEC, or low Apgar scores, in their 1986-1989 sample, similar years to Cohort 1. 
Within a neurobiological framework, the effects of neonatal morbidities may be seen as related to the high level of brain immaturity at preterm birth (Vohr \& Allen, 2005). Those infants of lower gestational ages may be particularly vulnerable to hypotensive and hypoxic injury, with the pattern of small lesion injury involving fibers to the limbs and motor pathways (Bracewell \& Marlow, 2002; Peterson et al., 2000). Also, perinatal infection and inflammatory cytokines associated with infection may exacerbate brain injury and result in high rates of neurodevelopmental impairment (Msall et al., 1991, 1994). Some evidence suggests that variations in motor impairment associated with preterm outcomes are a result of specific neuropathological processes affecting neuromotor pathways differently. For example, periventricular leukomalacia (PVL) and IVH are associated with gross motor delay, whereas fine motor and visual-motor integration deficits correlate with lesser degrees of neuromotor insult (Olsén, Pääkkö, Vainionpää, Pyhtinen, \& Järvelin, 1997). Some propose brain plasticity may account for differential effects in children who suffered neonatal injury. Extrapolating from animal models, Luciana (2003) suggested four possible developmental courses for preterm infants that offer insight for our results. In one course, injury is so severe that the child does not recover. In a second course, development proceeds despite evidence of injury. In the third, development may be compromised early, but the child improves with age. In the fourth, the developmental dysfunction becomes more evident as the child ages. In an expanded conceptual model, Aylward (2005) suggested that negative outcomes are not due to effects on one brain area per se, but to both disruptions of brain development resulting from injury and the interrelatedness of neural networks.

It is also possible that prematurity may produce deficits in development of the visual system (Aylward, 2005). The follow-up analyses showed an interplay between vision and motor performance. The preterm children of Cohort 2 had lower scores for visual motor integration than the preterm children of Cohort 1 . Visual motor function involves many components, including visuomotor control, visual perception, fine motor skill, and speed and eye-hand coordination. Hard, Niklasson, Svensson, and Hellstrom (2000) assessed both visual acuity and visual perception in children $<29$ weeks gestation and found decreased visual acuity even when eye disease was absent, suggesting that visual perception problems may be associated with brain lesions. Although Torrioli et al. (2000) found more deficits in visual motor integration and general motor ability in a sample of preterms with normal cerebral ultrasound (US) scans compared to full term controls, the use of MRI with preterm samples verifies PVL lesions more accurately than either US or computer tomography (CT; Skranes, Nilsen, Smevik, Vik, \& Brubakk, 1998), Thus, it is possible that had these technologies been available for some children in Cohort 1, more brain lesions, including PVL might have been diagnosed, which would account for their low visual motor scores.

In general, the likelihood of poor motor performance increases as birth weight decreases (Marlow, Roberts, \& Cooke, 1993). Foulder-Hughes and Cooke (2003) reported weak correlations (range $r=-.15$ to -.18 ) between birth weight and motor scores in their sample of 280 preterm children under 32 weeks gestation born in the early 1990s. However, minor motor disability and motor impairment of general motor, posture, coordination, and visual motor integration impairment were found throughout the birth weight range, while LevyShiff, Einat, Mogilner, Lerman, and Krikler (1994) reported that perinatal medical complications significantly predicted visual motor coordination over and above birth weight in their sample of 13-14-year-old VLBW children. In the present study as well, birth weight did not have an independent effect on preschool motor outcomes, although small significant correlations were found between birth weight and the five motor scores (range $r=.19-.31$ ). Only the correlation with oral motor scores was not significant. In many preterm outcomes studies, authors have used birth weight categories without full details on perinatal, neonatal, or post NICU morbidity. Our results suggest that this information should be provided in estimating preschool motor outcomes (Allen, 2002). 
Morbidity from prematurity may emerge after the perinatal period as developmental demands on motor abilities increase. Thus, early motor problems may not appear to improve with age. While attention has been focused on the smallest infants $(<1,000 \mathrm{~g})$, larger preterm infants represent a greater proportion of preterm births and are also at risk for neurodevelopmental sequelae (Amiel-Tison, Allen, Lebrun, \& Rogowski, 2002). Subtle long-term morbidities, referred to as "new morbidities", including difficulties in visual motor integration, learning and academic achievement, language, behavioral problems, and neurodevelopmental abnormalities, along with motor performance, have been identified in these children, as well (Ornstein, Ohlsson, Edmonds, \& Asztalos, 1991). Marlow and colleagues (Marlow, Roberts, \& Cooke, 1989; Marlow et al., 1993; Powls et al., 1995) followed a sample of children from the 1980s with birth weights $<1,250 \mathrm{~g}$ at ages 6,8 , and 12 and found no improvement in motor skills over time. However, Lunsing, Hadders-Algra, Huisjes, and Touwen (1992) reported improvements in motor performance for some children between age 9 and 12 years, where $22 \%$ of those impaired at age 9 were without impairment at age 12. Nevertheless, the extent of motor problems in preterm children may reveal why up to 50-70\% have subtle dysfunctions, such as learning disabilities, attention problems, cognitive deficits, neuropsychological deficits, and behavioral problems, which become evident at school age or later (Aylward, 2003).

Cohort comparison results add to our understanding of the full range of preterm motor sequelae within a timeframe of advancing neonatal technology. From a purely neurobiological framework, intervention might involve prenatal and postnatal technology and therapies, but this leaves out the whole range of environmental influences on motor development. In the post-natal environment, experiential and environmental influences may be able to improve outcomes (McGrath \& Sullivan, 1999, 2003). Due to the complex factors inherent in prematurity, it is essential that we have a better understanding of the factors that place children at risk for sequelae, that we are better able to identify children at risk for low severity dysfunctions, and that we understand the ways in which motor development can be compromised, in order to design appropriate interventions.

\section{Acknowledgments}

The authors wish to thank Margaret M. McGrath, DNSc, RN, FAAN, Principal Investigator of Cohort 1; Lewis Rubin, MD and Barry Lester, PhD for their consultation and expertise; and Christina Poore, MS, RNP and Melissa MacNeill, MA for assistance with assessment and data collection.

Contract grant sponsor: NIH; Contract grant numbers: RO1 NICHD1919, RO1 NINR NR02263, NICHD RO3 37627.

\section{References}

Al-Aweel I, Pursley DM, Rubin LP, Shah B, Weisberger SS, Richardson DK. Variations in prevalence of hypotension, hypertension, and vasopressor use in NICUs. Journal of Perinatology. 2001; 21:272-278. [PubMed: 11536018]

Allen MC. Preterm outcomes research: A critical component of neonatal intensive care. Mental Retardation and Developmental Disabilities Research Reviews. 2002; 8:221-233. [PubMed: 12454898]

Amiel-Tison C, Allen MC, Lebrun F, Rogowski J. Macropremies: Underprivledged newborns. Mental Retardation and Developmental Disabilities Research Review. 2002; 8:281-292.

Aylward GP. Cognitive and neuropsychological outcomes: More than IQ scores. Mental Retardation and Developmental Disabilities Research Reviews. 2002; 8:234-240. [PubMed: 12454899]

Aylward GP. Cognitive function in preterm infants: No simple answer. Journal of American Medical Association. 2003; 289:752-753. 
Aylward GP. Neurodevelopmental outcomes of infants born prematurely. Journal of Developmental and Behavioral Pediatrics. 2005; 26:427-440. [PubMed: 16344661]

Bednarek FJ, Weisberger S, Richardson DK, Frantz ID, Shah B, Rubin LP. Variations in blood transfusions among neonatal intensive care units. SNAP II Study Group. Journal of Pediatrics. 1998; 133:601-607. [PubMed: 9821414]

Beery, KE. Developmental test of visual-motor integration. Cleveland, OH: Modern Curriculum Press; 1982.

Beery, KE. The Beery-Buktenica developmental test of visual-motor integration. 4. Parsippany, NJ: Modern Curriculum Press; 1997.

Bell MJ, Ternberg JL, Feigin RD, Keating JP, Marshall R, Barton L, et al. Neonatal necrotizing enterocolitis: Therapeutic decisions based upon clinical staging. Annals of Surgery. 1978; 187:17. [PubMed: 413500]

Blitz RK, Wachtel RC, Blackmon L, Berenson-Howard J. Neurodevelopmental outcome of extremely low birth weight infants in Maryland. Maryland Medical Journal. 1997; 46:18-24. [PubMed: 9001122]

Bowen JR, Starte DR, Arnold JD, Simmons JL, Ma PJ, Leslie GI. Extremely low birthweight infants at 3 years: A developmental profile. Journal of Paediatrics \& Child Health. 1993; 29:276-281. [PubMed: 7690580]

Bracewell M, Marlow N. Patterns of motor disability in very preterm children. Mental Retardation and Developmental Disabilities Research Reviews. 2002; 8:241-248. [PubMed: 12454900]

Caravale B, Tozzi C, Albino G, Vicari S. Cognitive development in low risk preterm infants at 3-4 years of life. Archives of Disease in Childhood Fetal and Neonatal Edition. 2005; 90:F474-F479. [PubMed: 15956096]

Collin MF, Halsey CL, Anderson CL. Emerging developmental sequelae in the 'normal' extremely low birth weight infant. Pediatrics. 1991; 88:115-120. [PubMed: 1711669]

Creasey GL, Jarvis PA, Myers BJ, Markowitz PI, Kerkering KW. Mental and motor development in three groups of preterm infants: Differential effects of early medical complications. Infant Behavior and Development. 1993; 16:365-372.

Eriksson M, Bodin L, Finnstrom O, Schollin J. Can severity-of-illness indices for neonatal intensive care predict outcomes at 4 years of age? Acta Paediatrica. 2002; 91:1093-1100. [PubMed: 12434896]

Foulder-Hughes LA, Cooke RW. Motor, cognitive, and behavioral disorders in children born very preterm. Developmental Medicine \& Child Neurology. 2003; 45:97-103. [PubMed: 12578235]

Goyen TA, Lui K, Woods R. Visual-motor, visual-perceptual, and fine motor outcomes in very-lowbirthweight children at 5 years. Developmental Medicine \& Child Neurology. 1998; 40:76-81. [PubMed: 9489494]

Hack M, Fanaroff AA. Outcomes of children of extremely low birthweight and gestational age in the 1990s. Early Human Development. 1999; 53:193-218. [PubMed: 10088988]

Hard AL, Niklasson A, Svensson E, Hellstrom A. Visual function in school-aged children born before 29 weeks of gestation: A population-based study. Developmental Medicine and Child Neurology. 2000; 42:100-105. [PubMed: 10698327]

Hintze, J. NCSS and PASS [Computer software]. Kaysville, UT: Number Cruncher Statistical Systems; 2004.

Hobel CJ, Hyvarinen M, Okada D, Oh W. Prenatal and intrapartum high risk screening. American Journal of Obstetrics and Gynecology. 1973; 1:117.

Hollingshead, AB. Four factor index of social status. New Haven, CT: Yale University Press; 1975.

Kahn DJ, Richardson DK, Gray JE, Bednarek F, Rubin LP, Shah B, et al. Variation among neonatal intensive care units in narcotic administration. Archives of Pediatrics and Adolescent Medicine. 1998; 152:844-851. [PubMed: 9743028]

Lee KS, Kim B, Khoshnood B, Hsieh HL, Chen TJ, Mittendorf R. Outcome of very low birth weight infants in industrialized countries: 1947-1987. American Journal of Epidemiology. 1995; 141:1188-1193. [PubMed: 7771457] 
Levy-Shiff R, Einat G, Mogilner MB, Lerman MB, Krikler R. Biological and environmental correlates of developmental outcome of prematurely born infants in early adolescence. Journal of Pediatric Psychology. 1994; 19:63-78. [PubMed: 8151496]

Lie KG. Sensitivity of perceptuomotor measures for very low birth weight (VLBW $\leq 1500$ ) preschoolers. Child: Care, Health and Development. 1994; 20:239-249.

Luciana M. Cognitive development in children born preterm: Implications for theories of brain plasticity following early injury. Development and Psychopathology. 2003; 15:1017-1047. [PubMed: 14984136]

Lunsing RJ, Hadders-Algra M, Huisjes HJ, Touwen BCL. Minor neurological dysfunction from birth to 12 years. I: Increase during late school age. Developmental Medicine \& Child Neurology. 1992; 34:339-403.

Majnemer A, Riley P, Shevell M, Birnbaum R, Greenstone H, Coates AL. Severe bronchopulmonary dysplasia increases risk for later neurological and motor sequelae in preterm survivors. Developmental Medicine \& Child Neurology. 2000; 42:53-60. [PubMed: 10665976]

Marlow N, Roberts BL, Cooke RW. Motor skills in extremely low birthweight children at the age of 6 years. Archives of Disease in Childhood. 1989; 64:839-847. [PubMed: 2476079]

Marlow N, Roberts BL, Cooke RW. Outcome at 8 years for children with birthweights of 1250 grams or less. Archives of Disease in Childhood. 1993; 68:286-290. [PubMed: 8466264]

Martin JA, Hamilton BE, Sutton PD, Ventura SJ, Menacker F, Kirmeyer S. Births: Final data for 2004. National Vital Statistics Reports. 2006; 55(1):1-26.

McCarthy, D. McCarthy scales of children's abilities. New York: The Psychological Corporation; 1972.

McGrath MM, Sullivan MC. Medical and ecological factors in estimating motor outcomes in preschool children. Research in Nursing \& Health. 1999; 22:155-167. [PubMed: 10094300]

McGrath MM, Sullivan MC. Testing proximal and distal protective processes in preterm high risk children. Issues in Comprehensive Pediatric Nursing. 2003; 26:59-76. [PubMed: 12850997]

Ment LR, Oh W, Ehrenkrantz RA, Phillip AG, Vohr B, Allan W, et al. Low dose indomethacin therapy and extension of intraventricular hemorrhage: A multi center randomized trial. The Journal of Pediatrics. 1994; 124:951-955. [PubMed: 8201485]

Msall ME, Buck GM, Rogers BT, Merke DP, Catanzaro NL, Zorn WA. Risk factors for major neurodevelopmental impairments and need for special education resources in extremely premature infants. Journal of Pediatrics. 1991; 119:606-614. [PubMed: 1919894]

Msall ME, Buck GM, Rogers BT, Merke DP, Wan CC, Catanzaro NL, et al. Multivariate risks among extremely premature infants. Journal of Perinatology. 1994; 14:41-47. [PubMed: 8169677]

Olsén P, Pääkkö E, Vainionpää L, Pyhtinen J, Järvelin MR. Magnetic resonance imaging of periventricular leukomalacia and its clinical correlation in children. Annals of Neurology. 1997; 41:754-761. [PubMed: 9189036]

Ornstein M, Ohlsson A, Edmonds J, Asztalos E. Neonatal follow-up of very low birth weight/ extremely low birth weight infants to school age: A critical overview. Acta Paediatrica Scandinavia. 1991; 80:741-748.

O'Shea TM, Klinepeter KL, Goldstein DJ, Jackson BW, Dillard RG. Survival and developmental disability in infants with birth weights of 501 to 800 grams, born between 1979 and 1994 . Pediatrics. 1997; 100:982-986. [PubMed: 9374569]

Papile LA, Burstein J, Burstein R, Koffler H. Incidence and evaluation of subependymal and intraventricular hemorrhage: A study of infants with birth weights less than 1,500 gm. The Journal of Pediatrics. 1978; 92:529-534. [PubMed: 305471]

Peterson BS, Vohr B, Staib LH, Cannistraci CJ, Dolberg A, Schneider KC, et al. Regional brain volume abnormalities and long-term cognitive outcomes in preterm infants. Journal of American Medical Association. 2000; 284:1939-1947.

Piecuch RE, Leonard CH, Cooper BA, Kilpatrick SJ, Schlueter MA, Sola A. Outcome of infants born at 24-26 weeks' gestation. II. Neurodevelopmental outcome. Obstetrics \& Gynecology. 1997; 90:809-814. [PubMed: 9351769] 
Powls A, Botting N, Cooke RW, Marlow N. Motor impairment in children 12 to 13 years old with a birthweight of less than 1250 grams. Archives of Disease in Childhood Fetal and Neonatal Edition. 1995; 73:F62-F66. [PubMed: 7583608]

Richardson, DK. SNAP-II Scoring Manual, Version 1.1. Kaiser Permante, Beth Israel Deaconess Medical Center, University of British Columbia, Children's \& Women's Health Centre of British Columbia; 1999.

Richardson DK, Corcoran JD, Escobar GE, Lee SK. Snap-II and Snappe-II: Simplified newborn illness severity and mortality risk scores. Journal of Pediatrics. 2001; 138:92-100. [PubMed: 11148519]

Richardson DK, Shah B, Frantz ID, Bednarek F, Rubin LP, McCormick MC. Perinatal risk and severity of illness in newborns at 6 neonatal intensive care units. American Journal of Public Health. 1999; 89:511-516. [PubMed: 10191793]

Riley, GD. Riley motor problems inventory (manual). Los Angeles, CA: Western Psychological Services; 1976.

Saigal S, Feeny D, Furlong W, Rosenbaum P, Burrows E, Torrance G. Comparison of the healthrelated quality of life of extremely low birth weight children and a reference group of children at age eight years. Journal of Pediatrics. 1994; 125:418-425. [PubMed: 8071752]

Shevall MI, Majnemer A. Clinical features of developmental disability associated with cerebral hypoplasia. Pediatric Neurology. 1996; 15:224-229. [PubMed: 8916160]

Singer L, Yamashita T, Lilien L, Collin M, Baley J. A longitudinal study of developmental outcome of infants with bronchopulmonary dysplasia and very low birth weight. Pediatrics. 1997; 100:987993. [PubMed: 9374570]

Skranes JS, Nilsen G, Smevik O, Vik T, Brubakk AM. Cerebral MRI of very low birth weight children at 6 years of age compared with the findings at 1 year. Pediatric Radiology. 1998; 28:471-475. [PubMed: 9634467]

Smith VC, Zupanic JA, McCormick MC, Croen LA, Greene J, Escobar GJ, et al. Trends in severe bronchopulmonary dysplasia rates between 1994 and 2002. Journal of Pediatrics. 2005; 146:469473. [PubMed: 15812448]

Stjernqvist K, Svenningsen NW. Extremely low-birth-weight infants less than $901 \mathrm{~g}$ : Development and behavior after 4 years of life. Acta Paediatrica. 1995; 84:500-506. [PubMed: 7633143]

Stoelhorst GM, Rijken M, Martens SE, Brand R, den Ouden AL, Wit JM, et al. Changes in neonatology: Comparison of two cohorts of very preterm infants (gestational age <32 weeks): The Project on Preterm and Small for Gestational Age Infants 1983 and The Leiden Follow-Up Project on Prematurity 1996-1997. Pediatrics. 2005; 115:396-405. [PubMed: 15689337]

Sullivan MC, McGrath MM. Perinatal morbidity, mild motor delay, and later school outcomes. Developmental Medicine \& Child Neurology. 2003; 45:104-112. [PubMed: 12578236]

Taylor HG, Burant CJ, Holding PA, Klein N, Hack M. Sources of variability in sequelae of very low birth weight. Child Neuropsychology. 2002; 8:163-178. [PubMed: 12759832]

Torrioli MG, Friscone MF, Bonvoni L, Luciano R, Pasca MG, Lepori R, et al. Perceptual-motor, visual and cognitive ability in very low birthweight preschool children without neonatal ultrasound abnormalities. Brain Development. 2000; 22:163-168. [PubMed: 10814898]

Touwen BC, Hempel MS, Westra LC. The development of crawling between 18 months and four years. Developmental Medicine \& Child Neurology. 1992; 34:410-416. [PubMed: 1592193]

Vohr B, Wright LL, Dusick AM, Perritt R, Poole WK, Tyson JE, et al. Center differences and outcomes of extremely low birth weight infants. Pediatrics. 2004; 113:781-789. [PubMed: 15060228]

Vohr BR, Allen M. Extreme prematurity-The continuing dilemma. New England Journal of Medicine. 2005; 352:71-72. [PubMed: 15635115]

Vohr BR, Msall ME. Neuropsychological and functional outcomes of very low birth weight infants. Seminars in Perinatology. 1997; 21:202-220. [PubMed: 9205976]

Volpe JJ. Neurological outcome of prematurity. Archives of Neurology. 1998; 55:297-300. [PubMed: 9520002]

Volpe JJ. Brain injury in the premature infants-From pathogenesis to prevention. Brain \& Development. 1997; 19:519-534. [PubMed: 9440796] 
Wildin SR, Smith K, Anderson A, Swank P, Denson S, Landry S. Prediction of developmental patterns through 40 months from 6-and 12-month neurologic examinations in very low birth weight infants. Developmental and Behavioral Pediatrics. 1997; 18:215-221.

Women \& Infants Hospital. Annual birth statistics for Women \& Infants Hospital. Providence, RI: 1999. 

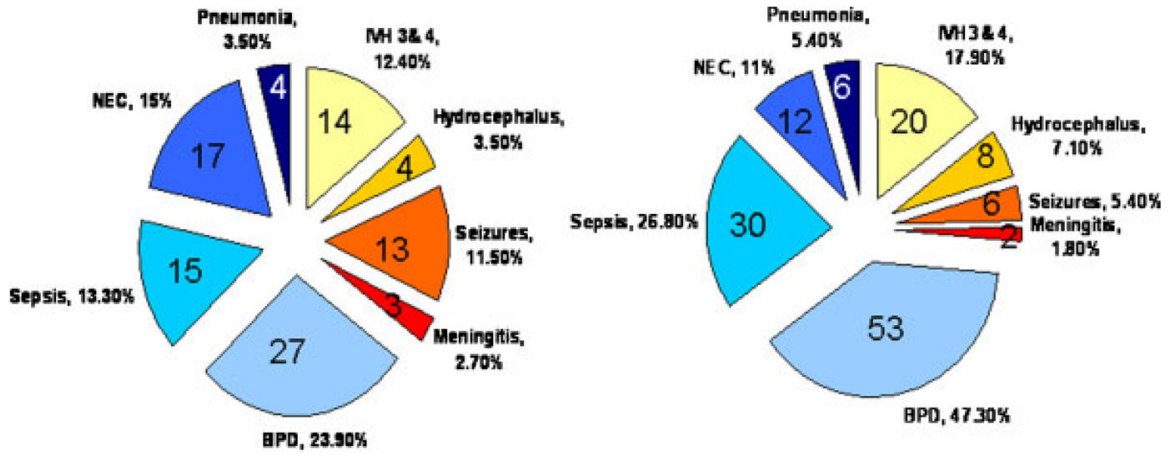

FIGURE 1.

Frequency of Preterm Medical \& Neurological Morbidities for Each Cohort. 




FIGURE 2.

Frequency of Co-existing Medical Morbidities in NPT Groups for Each Cohort. 
Table 2

Significant Mean Motor Score Differences Between Cohort and Groups

\begin{tabular}{|c|c|c|c|c|}
\hline \multirow[b]{2}{*}{ Motor Measures } & \multicolumn{4}{|c|}{$M(S E)$} \\
\hline & Total Sample & MPT1 & MPT2 & NPT \\
\hline Beery VMI SS & $\begin{array}{c}18.1(1.9)^{* * *} \\
(\mathrm{C} 1>\mathrm{C} 2)\end{array}$ & $\begin{array}{c}14.17(4.9)^{*} \\
(\mathrm{C} 1>\mathrm{C} 2)\end{array}$ & $\begin{array}{c}15.58(2.87)^{* *} \\
(\mathrm{C} 1>\mathrm{C} 2)\end{array}$ & $\begin{array}{c}21.9(4.5)^{* *} \\
(\mathrm{C} 1>\mathrm{C} 2)\end{array}$ \\
\hline RMPI oral & $\begin{array}{c}1.01(.192)^{* * *} \\
(\mathrm{C} 2>\mathrm{C} 1)\end{array}$ & $\begin{array}{c}1.76(.39)^{* *} \\
(\mathrm{C} 2>\mathrm{C} 1)\end{array}$ & $\begin{array}{c}1.23(.35)^{* *} \\
(\mathrm{C} 2>\mathrm{C} 1)\end{array}$ & \\
\hline RMPI fine & $\begin{array}{l}.812(.182)^{* *} \\
(\mathrm{C} 2>\mathrm{C} 1)\end{array}$ & $\begin{array}{l}1.4(.39)^{* * *} \\
(\mathrm{C} 2>\mathrm{C} 1)\end{array}$ & & \\
\hline RMPI total & $\begin{array}{c}2.16(.45)^{* *} \\
(\mathrm{C} 2>\mathrm{C} 1)\end{array}$ & $\begin{array}{c}3.88(1.0)^{* * *} \\
(\mathrm{C} 2>\mathrm{C} 1)\end{array}$ & $\begin{array}{l}2.4(2.87)^{* *} \\
(\mathrm{C} 2>\mathrm{C} 1)\end{array}$ & \\
\hline
\end{tabular}

Note. Groups: MPT1, medically ill preterm group, birth weight <1,000 g; MPT2, medically ill preterm group birth weight $21,000 \mathrm{~g}$; NPT, neurologically ill preterm group; $\mathrm{C} 1>\mathrm{C} 2$, Cohort 1 mean score is greater than Cohort 2; $2>\mathrm{C} 1$, Cohort 2 mean score is greater than Cohort 1; RMPI, Riley Motor Problem Inventory; VMIss, Developmental Test of Visual Motor Integration.

$* p=.01$.
$* *$
$p=.001$. 


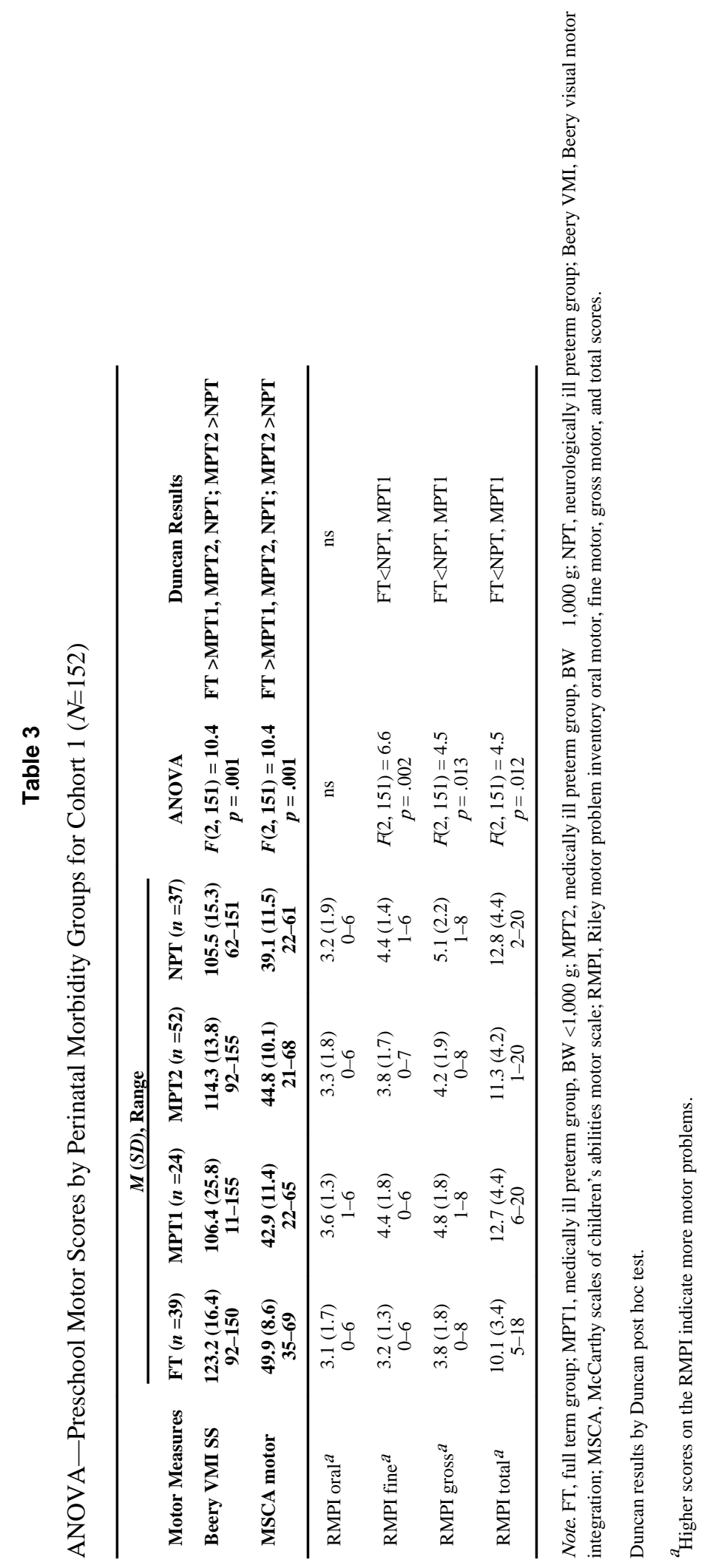




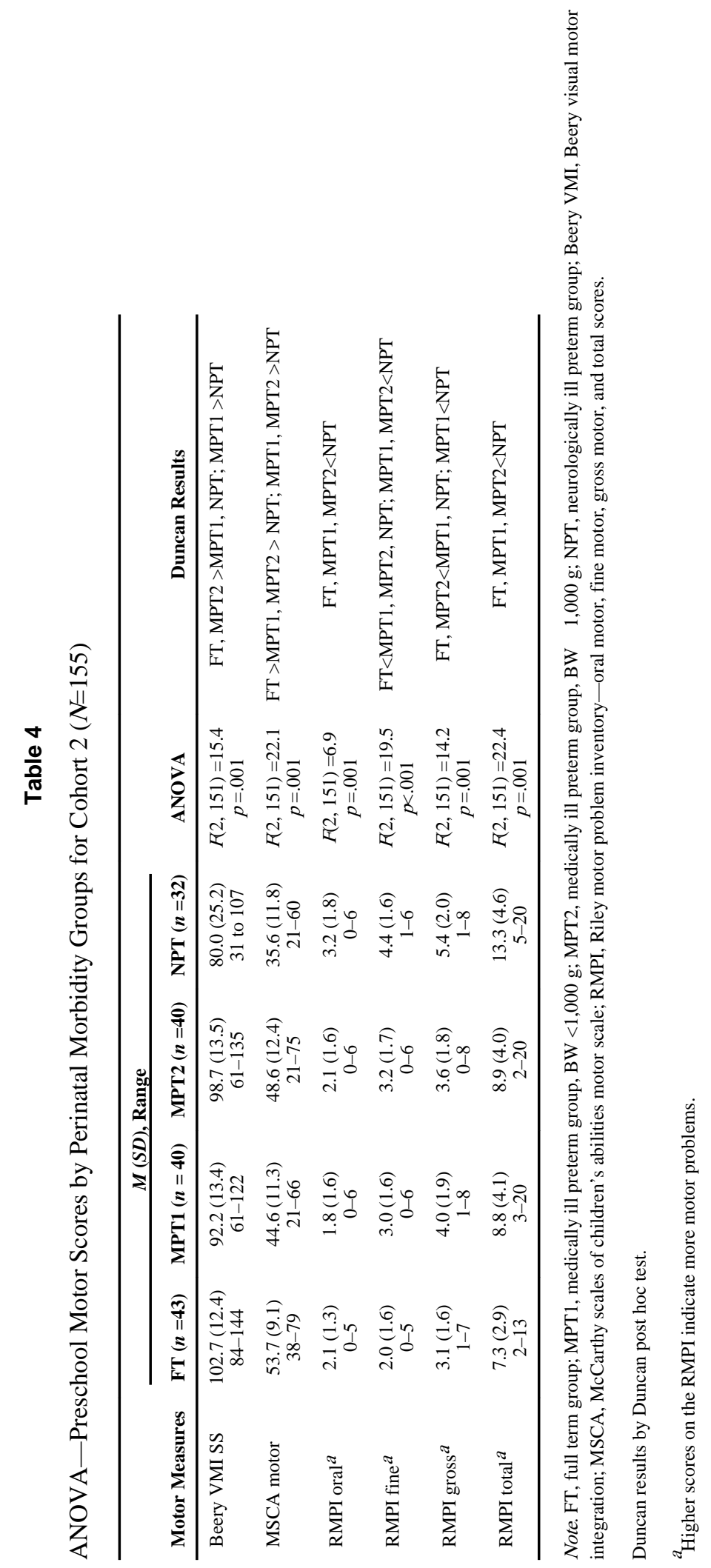

